\title{
Potentialities of multi-b-values diffusion- weighted imaging for predicting efficacy of concurrent chemoradiotherapy in cervical cancer patients
}

Bing Liu ${ }^{1+}$, Wan-Ling Ma ${ }^{2+}$, Guang-Wen Zhang ${ }^{1}$, Zhen Sun ${ }^{3}$, Meng-Qi Wei ${ }^{1}$, Wei-Huan Hou', Bing-Xin Hou', Li-Chun Wei ${ }^{4}$ and Yi Huan ${ }^{1 *}$

\begin{abstract}
Background: To testify whether multi-b-values diffusion-weighted imaging (DWI) can be used to ultra-early predict treatment response of concurrent chemoradiotherapy (CCRT) in cervical cancer patients and to assess the predictive ability of concerning parameters.

Methods: Fifty-three patients with biopsy proved cervical cancer were retrospectively recruited in this study. All patients underwent pelvic multi-b-values DWI before and at the 3rd day during treatment. The apparent diffusion coefficient (ADC), true diffusion coefficient $\left(D_{\text {slow }}\right)$, perfusion-related pseudo-diffusion coefficient $\left(D_{\text {fast }}\right)$, perfusion fraction $(f)$, distributed diffusion coefficient (DDC) and intravoxel diffusion heterogeneity index(a) were generated by mono-exponential, bi-exponential and stretched exponential models. Treatment response was assessed based on Response Evaluation Criteria in Solid Tumors (RECIST v1.1) at 1 month after the completion of whole CCRT. Parameters were compared using independent $t$ test or Mann-Whitney $U$ test as appropriate. Receiver operating characteristic (ROC) curves was used for statistical evaluations.

Results: ADC-T0 $(p=0.02), \mathrm{D}_{\text {slow }}{ }^{-T 0}(p<0.01), \mathrm{DDC}-\mathrm{T0}(p=0.03), \mathrm{ADC}^{-T 1}(p<0.01), \mathrm{D}_{\text {slow }}{ }^{-T 1}(p<0.01), \Delta \mathrm{ADC}$ $(p=0.04)$ and $\Delta a(p<0.01)$ were significant lower in non-CR group patients. ROC analyses showed that ADC-T1 and $\Delta a$ exhibited high prediction value, with area under the curves of 0.880 and 0.869 , respectively.

Conclusions: Multi-b-values DWI can be used as a noninvasive technique to assess and predict treatment response in cervical cancer patients at the 3rd day of CCRT. ADC-T1 and $\Delta a$ can be used to differentiate good responders from poor responders.
\end{abstract}

Keywords: Cervical cancer, Diffusion magnetic resonance imaging, Concomitant Chemoradiotherapy

\footnotetext{
* Correspondence: huanyi3000@163.com

${ }^{+}$Bing Liu and Wan-Ling Ma contributed equally to this work.

'Department of Radiology, Xijing Hospital, Fourth Military Medical University,

127 Changle Western Road, Xi'an, P. R. China 710032

Full list of author information is available at the end of the article
}

\section{$\triangle B M C$}

(c) The Author(s). 2020 Open Access This article is licensed under a Creative Commons Attribution 4.0 International License, which permits use, sharing, adaptation, distribution and reproduction in any medium or format, as long as you give appropriate credit to the original author(s) and the source, provide a link to the Creative Commons licence, and indicate if changes were made. The images or other third party material in this article are included in the article's Creative Commons licence, unless indicated otherwise in a credit line to the material. If material is not included in the article's Creative Commons licence and your intended use is not permitted by statutory regulation or exceeds the permitted use, you will need to obtain permission directly from the copyright holder. To view a copy of this licence, visit http://creativecommons.org/licenses/by/4.0/. The Creative Commons Public Domain Dedication waiver (http://creativecommons.org/publicdomain/zero/1.0/) applies to the data made available in this article, unless otherwise stated in a credit line to the data. 


\section{Background}

Diffusion-weighted imaging (DWI) is sensitive to water molecular diffusion within biological tissues. Apparent diffusion coefficient (ADC) derived from monoexponential model (MEM) is still the most adopted parameter in guiding daily clinical work nowadays. The $\mathrm{ADC}$ values may not reflect water diffusion in tissue accurately, because it is also influenced by the microcirculation perfusion in capillaries [1]. Based on biexponential model (BEM), multi-b-values DWI might enable to separate the microcirculation perfusion from true diffusion [1, 2]. Stretched exponential model (SEM) offers information on heterogeneity of intravoxel diffusion rates and the distributed diffusion effect, thus providing complementary information of tissue property [3]. MEM, BEM and SEM DWI models have already been applied as imaging biomarker to predict and assess treatment response in rectal cancer, head and neck squamous cell carcinoma, breast cancer, prostate cancer and esophageal squamous cell carcinoma [4-15]. Several reports revealed that MEM, BEM and SEM DWI models could be used in the diagnosis, differentiation and separation of type and grade in cervical cancer (CC) [16, 17]. BEM DWI models were useful for predicting and monitoring the treatment efficacy CC patients [18-20], but results were contradictory. To date, SEM DWI models has not been used in the prediction and assessment of treatment response in CC.

Treatment options differ according to tumor Federation of Gynecology and Obstetrics (FIGO) stage and lymph node status; early-stage disease (IA and IB1) is treated by surgery alone, whereas locally advanced (IB2, IIA2 and IIB to IVA) or lymph node positive diseases is treated with CCRT. It is generally agreed that tumor volume diminish is a favorable indicator of good treatment response [21, 22] and volume reduction is related with local control in CC patients underwent concurrent chemoradiotherapy (CCRT) [23]. Currently researches concerning treatment response prediction mainly focus on parameters change at 1 week and 4 weeks after treatment initiation [19, 24, 25], but no earlier time-points have been evaluated. With the increase of chemoradiotherapy dose, toxicity and adverse side effects aggravate in CC patients during CCRT. Therefore, it is valuable to search an ultra-early time-point to evaluate the treatment response. Tumor molecular changes generally happen earlier than morphological change during CCRT in CC. In order to search an earlier time-point to identify good responders from poor responders, we set the completion of third external beam radiotherapy (EBRT) (at a dose of 6 Gy) as ultra-early monitoring point by using multi-b-values DWI. In order to investigate tumor diffusion property change accurately during CCRT between good and poor responders, mono-exponential, bi-exponential, and stretched exponential DWI models were performed.

The present study aimed to search for a potential early imaging biomarker to predict treatment response of CCRT in CC patients at early stage by using multi-bvalues DWI parameters.

\section{Methods \\ Patients}

This study was approved by the ethics committee of Institutional Review Board of our hospital, and written informed consents were obtained from all patients before participation. Between Nov 2018 and May 2019, 53 consecutive patients with histologically proven untreated CC scheduled to undergo CCRT treatment were enrolled in this retrospective study. The exclusion criteria were contradictions for MR scanning or CCRT. There was no dropout in our research.

\section{CCRT treatment}

All patients were treated with a combination of EBRT and intracavitary brachytherapy (ICBT). EBRT was delivered to the whole pelvis, with a total dose of $50 \mathrm{~Gy}$ (daily dose of 2 Gy, 5 times per week) and accompanied by concurrent chemotherapy: six cycles of weekly cisplatin $\left(40 \mathrm{mg} / \mathrm{m}^{2}\right)$ or three cycles of cisplatin $\left(75 \mathrm{mg} / \mathrm{m}^{2}\right)$ at 3 week intervals. ICBT was initiated after an EBRT dose of 46-50 Gy. ICBT was delivered once or twice a week in 4-5 fractions, with a fractional dose of 6-7 Gy at point A. The median dose of ICBT was $28 \mathrm{~Gy}$ and the median biological effective dose (BED) was 47.8 Gy (range, 23.3$64.7 \mathrm{~Gy})$ to point A.

\section{MRI protocol}

All patients underwent MR examination at two timepoints: within 1 week before (T0) and the 3rd day during (T1) CCRT. All MR examinations were performed on a 3.0 T MRI scanner (GE Healthcare 750 Discovery, Milwaukee, Wisconsin, USA) using an 8-channel phase array coil. Routine MRI protocols included sagittal T2WI (repetition time [TR]/echo time [TE]: 4763 /85 ms; slice thickness/spacing: $4 / 0.4 \mathrm{~mm}$; field of view [FOV]: $28 \mathrm{~cm}$; number of excitations [NEX]: 4), coronal T2WI (TR/TE: 4171 /85 ms; slice thickness/spacing: 5 / $0.5 \mathrm{~mm}$; FOV: $32 \mathrm{~cm}$; NEX: 4), axial T2WI with fat suppression (TR/TE: 4580 /85 ms; slice thickness/spacing: 4 /1 mm; FOV: $34 \mathrm{~cm}$; NEX: 4), axial T1WI (TR/TE: 601 /minimum ms; slice thickness/spacing: $3 / 1 \mathrm{~mm}$; FOV: $32 \mathrm{~cm}$; NEX: 2). Axial multi-b-values DWI with $11 \mathrm{~b}-$ values of $0,10,20,40,80,150,200,400,800,1000$ and $1200 \mathrm{~s} / \mathrm{mm}^{2}$ was performed with a single-shot echoplanar sequence (TR/TE: 3883 /59 ms; slice thickness/ spacing: $5 / 0.5 \mathrm{~mm}$; FOV: $36 \mathrm{~cm}$; matrix, $128 \times 160$; NEX 
1 to 6 with the increasing of b-values, total scan time 6 : $34 \mathrm{~min})$.

\section{Treatment response assessment}

Treatment response was assessed at 1 month after the completion of the entire CCRT by using convention MR scanning according to the evaluation criteria in solid tumors (RECIST v1.1 [26]) as follows: (1) complete response (CR): no residual tumor showed on the MR images; (2) partial response (PR): the largest diameter of residual tumor was at least $30 \%$ less than the original size; (3) progressive disease (PD): there was an at least $20 \%$ increase in the longest diameter of tumor compared with the pretreatment size; (4) stable disease (SD): there was neither a decrease sufficient to qualify for PR nor an increase sufficient to qualify for PD. All patients were dichotomized into two groups, CR group and non-CR group. The CR group consisted of patients with $\mathrm{CR}$, while non-CR group consisted of patients with PR, SD and PD.

\section{Image analysis}

Two radiologists with 15 and 2 years' experience in gynecologic imaging performed post-process and image analysis independently. Readers were blinded to the pathological findings and therapeutic responses. All functional parameters maps were post-processed by using the MADC program on the Advantage Workstation (AW 4.6 version, GE, US). The regions of interest (ROIs) containing all the tumor region and avoiding obvious necrotic areas were manually delineated along the margin of tumor on the three consecutive maximal tumor slices on axial DWI images with $b=1000 \mathrm{~s} / \mathrm{mm}^{2}$. The mean value of parameters of the three ROIs was used for statistical analysis.

The mono-exponential model was applied to calculate $\mathrm{ADC}$ value from all $11 \mathrm{~b}$ values by using the following equation [1]:

$$
\mathrm{S} / \mathrm{S}_{0}=\exp (-\mathrm{b} \cdot \mathrm{ADC})
$$

Where $\mathrm{S}_{0}$ and $\mathrm{S}$ represent the signal intensity obtained with the $\mathrm{b}=0$ and $\mathrm{b}>0 \mathrm{~s} / \mathrm{mm}^{2}$.

The bi-exponential model, also called intravoxel incoherent motion (IVIM), was applied to calculate $\mathrm{D}_{\text {slow }}$, $D_{\text {fast }}$ and $f_{p}$ values with the following equation [27]:

$$
\begin{aligned}
\mathrm{S}_{\mathrm{b}} / \mathrm{S}_{0}= & \left(1-\mathrm{f}_{\mathrm{p}}\right) \cdot \exp \left(-\mathrm{b} \cdot \mathrm{D}_{\text {slow }}\right)+\mathrm{f}_{\mathrm{p}} \\
& \cdot \exp \left(-\mathrm{b} \cdot \mathrm{D}_{\text {fast }}\right)
\end{aligned}
$$

Where $S_{\mathrm{b}}$ represents the mean signal intensity with diffusion gradient $b$, and $S_{0}$ represents the mean signal intensity at $b=0 \mathrm{~s} / \mathrm{mm}^{2}$. The $f_{p}$ (perfusion fraction) represents the ratio of water movement within capillaries compared with the total volume of water in a voxel.
$\mathrm{D}_{\text {slow }}$ (pure diffusion coefficient) represents pure molecular diffusion where a physiological perfusion effect is excluded. $\mathrm{D}_{\text {fast }}$ (pseudo-diffusion coefficient) represents the average blood velocity and mean capillary segment length. Considering that $\mathrm{D}_{\text {fast }}$ is much greater than $\mathrm{D}_{\text {slow }}$ with one order of magnitude, the effects of $D_{\text {fast }}$ on the signal decay at large b-values $\left(>200 \mathrm{~s} / \mathrm{mm}^{2}\right)$ can be ignored.

The stretched exponential model was used to calculate DDC and $\alpha$ by using the following equation [3]:

$$
\mathrm{S} / \mathrm{S}_{0}=\exp \left(-(\mathrm{b} \cdot \mathrm{DDC})^{\alpha}\right)
$$

Where $\mathrm{S}_{0}$ and $\mathrm{S}$ represents the signal intensity obtained with the $\mathrm{b}=0$ and $\mathrm{b}>0 \mathrm{~s} / \mathrm{mm}^{2}$. DDC represents the distributed diffusion coefficient reflecting the mean intravoxel diffusion rate, while $\alpha$ represents intravoxel diffusion heterogeneity index corresponding to intravoxel water molecular diffusion heterogeneity with a range from 0 to 1 [28].

\section{Statistical analysis}

All statistical analyses were performed using SPSS (Version 17.0, SPSS Inc., Chicago, IL, USA) and GraphPad Prism 5 (GraphPad Prism Software Inc., San Diego, California, USA). An intra-class correlation coefficient (ICC) was calculated to evaluate interobserver reliability of the measurements. Change of MRI parameters $(\Delta)$ was defined as (parameter-T1-parameter-T0)。All quantitative values are presented as the mean \pm standard deviation (SD). Clinical characteristics of cervical cancer patients with different treatment outcome was compared using Chi-square test. The Kolmogorov-Smirnov test was conducted to analyze the normal distribution of all

Table 1 Clinical characteristics between cervical cancer patients with different treatment outcome

\begin{tabular}{lllll}
\hline Clinical characteristics & CR & non-CR & $t$ or $X^{2}$ & $p$ \\
\hline Number of patients & 35 & 18 & & \\
Age (years) & 52.4 & 51.7 & $0.36^{\mathrm{a}}$ & 0.72 \\
FIGO stage & 17 & 8 & $0.08^{\mathrm{b}}$ & 0.78 \\
$\quad$ II & 18 & 10 & & \\
$\quad$ III+ IV & & & $1.67^{\mathrm{b}}$ & 0.20 \\
Histology & 33 & 15 & & \\
$\quad$ Squamous cell carcinoma & 2 & 3 & & \\
$\quad$ Adenocarcinoma & & & $0.58^{\mathrm{b}}$ & 0.45 \\
Lymph node status & 25 & 11 & & \\
$\quad$ Positive & 10 & 7 & & \\
$\quad$ Negative &
\end{tabular}

Note: Data are number (\%) or mean (range), FIGO The International Federation of Gynecology and Obstetrics, $C R$ Complete response. ${ }^{\text {a }}$ Comparisons were performed by independent $\mathrm{t}$ test. ${ }^{\mathrm{b}}$ Comparisons were performed by Chi-square test 


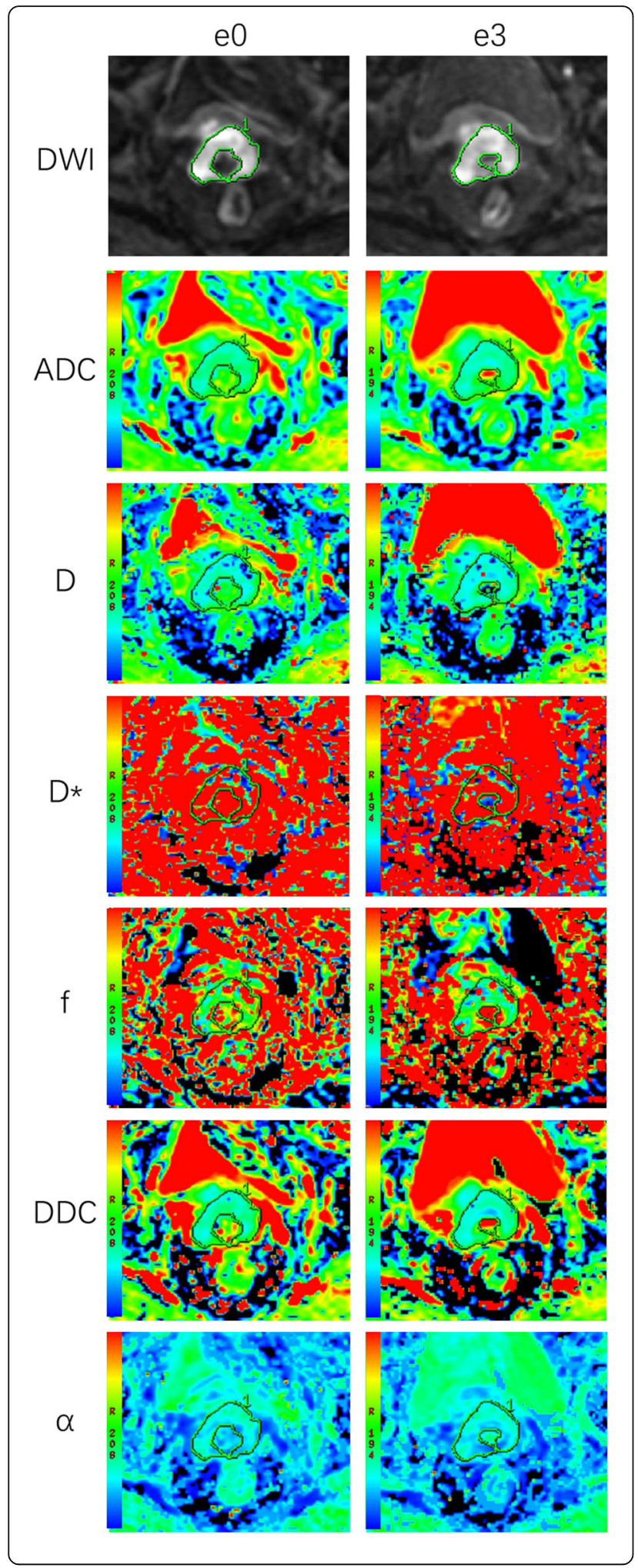

Fig. 1 A cervical cancer patient from the complete response group. Images in first line were $D W l, A D C, D_{\text {slow, }} D_{\text {fast }} f_{p}$, $D D C$ and a maps at TO(before CCRT). The ADC, $D_{\text {slow, }} D_{\text {fast }}, f_{p}, D D C$ and a values were $0.97 \times 10^{-3} \mathrm{~mm}^{2} / \mathrm{s}, 0.61 \times 10^{-3} \mathrm{~mm}^{2} / \mathrm{s}, 99.02 \times 10^{-3} \mathrm{~mm}^{2} / \mathrm{s}, 0.21$, $0.92 \times 10^{-3} \mathrm{~mm}^{2} / \mathrm{s}$ and 0.76 , respectively. Images in second line were DWI, ADC, D, D*, f, DDC and a at T1 (the 3rd day during CCRT) of the same patient. The $A D C, D_{\text {slow, }}, D_{\text {fast }}, f_{p}, D D C$ and a values were $1.71 \times$ $10^{-3} \mathrm{~mm}^{2} / \mathrm{s}, 1.44 \times 10^{-3} \mathrm{~mm}^{2} / \mathrm{s}, 81.82 \times 10^{-3} \mathrm{~mm}^{2} / \mathrm{s}, 0.23,2.53 \times 10^{-3}$ $\mathrm{mm}^{2} / \mathrm{s}$ and 0.65 , respectively

metrics. Comparisons between $\mathrm{CR}$ group and non-CR group, and between different time-points were performed by using independent $t$ test $\left(\mathrm{D}_{\text {slow }}, \mathrm{DDC}\right.$ and $\alpha$, which conformed to normal distribution) and MannWhitney $U$ test $\left(A D C, D_{\text {fast }}\right.$ and $f_{p}$, which did not conform to normal distribution). Two-tailed $p$ values were used and $\mathrm{p}$ values less than 0.05 were considered as statistically significant. The area under the curve (AUC) of the receiver operating characteristic (ROC) curves for the significant parameters were calculated and compared. The cut-off values were selected by using the maximized values of the Youden indexes. The values that corresponded to the highest Youden index were chosen as the optimal threshold values.

\section{Results}

\section{Patients and treatment characteristics}

Patients and treatment characteristics were listed in Table 1. The final study cohort included 53 CC patients with FIGO II-IVB disease (mean age: 51.2 years, range $27-$ 67 years). One month after the completion of CCRT, MRI examination showed that 35 of the 53 patients $(66.04 \%)$ achieved CR and 18 patients (33.96\%) achieved incomplete response. No significant differences were observed between patient groups in terms of clinical characteristics. Figures 1 and 2 provided functional parameter maps of $\mathrm{CR}$ and non-CR patients before and during CCRT.

\section{Interobserver agreement in imaging analysis}

The intraclass correlation coefficients (ICCs) of all parameters were ranging between 0.852 to 0.934 , which means the measurements of MEM, BEM and SEM derived parameters had good interobserver reproducibility. Details were presented in Table 2.

\section{Comparison of MRI parameters between CR group and non-CR group}

The differences of ADC, $D_{\text {slow, }}, D_{\text {fast }}, f_{p}, D D C$ and $\alpha$ values between patients with different clinical outcome were presented in Table 3 . Our results revealed that pretreatment ADC-T0 $\left(0.94 \times 10^{-3}\right.$ vs $1.08 \times 10^{-3} \mathrm{~mm}^{2} / \mathrm{s}$, $p=0.02), \mathrm{D}_{\text {slow }}-\mathrm{T} 0\left(0.76 \times 10^{-3}\right.$ vs $0.93 \times 10^{-3} \mathrm{~mm}^{2} / \mathrm{s}$, $p<0.01)$ and DDC-T0 $\left(1.02 \times 10^{-3}\right.$ vs $1.20 \times 10^{-3}$ $\left.\mathrm{mm}^{2} / \mathrm{s}, p=0.02\right)$ was significantly lower in non-CR 


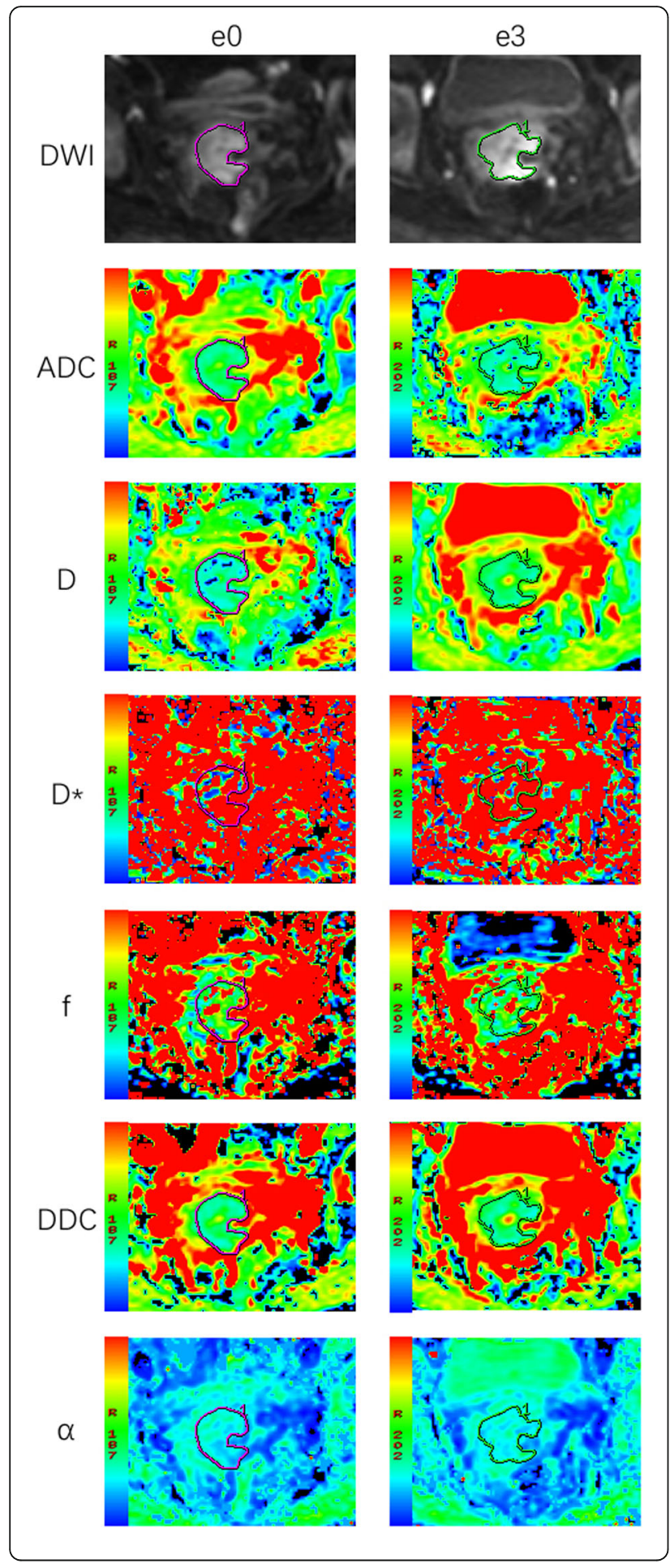

Fig. 2 A cervical cancer patient from the non-complete response group. Images in first line were DWI, ADC, $D_{\text {slow, }} D_{\text {fast }}, f_{p}$, DDC and a maps at T0 (before CCRT). The ADC, $D_{\text {slow, }}, D_{\text {fast, }}, f_{p}, D D C$ and a values were $1.04 \times 10^{-3} \mathrm{~mm}^{2} / \mathrm{s}, 0.90 \times 10^{-3} \mathrm{~mm}^{2} / \mathrm{s}, 99.02 \times 10^{-3} \mathrm{~mm}^{2} / \mathrm{s}$, $0.15,0.33 \times 10^{-3} \mathrm{~mm}^{2} / \mathrm{s}$ and 0.70 , respectively. Images in second line were $D W I, A D C, D, D^{*}, f, D D C$ and $a$ at $T 1$ (the 3rd day during CCRT) of the same patient. The ADC, $D_{\text {slow }}, D_{\text {fast }}, f_{p}, D D C$ and a values were $1.06 \times 10^{-3} \mathrm{~mm}^{2} / \mathrm{s}, 0.81 \times 10^{-3} \mathrm{~mm}^{2} / \mathrm{s}, 76.42 \times 10^{-3} \mathrm{~mm}^{2} / \mathrm{s}, 0.22$, $1.06 \times 10^{-3} \mathrm{~mm}^{2} / \mathrm{s}$ and 0.76 , respectively

group patients. At the 3rd day during CCRT, ADC-T1 $\left(1.26 \times 10^{-3}\right.$ vs $\left.1.00 \times 10^{-3} \mathrm{~mm}^{2} / \mathrm{s}, p<0.01\right)$ and $\mathrm{D}_{\text {slow }}{ }^{-}$ T1 $\left(1.07 \times 10^{-3}\right.$ vs $\left.0.92 \times 10^{-3} \mathrm{~mm}^{2} / \mathrm{s}, p<0.01\right)$ were significantly higher in $\mathrm{CR}$ group patients. Between the two time-points, the changes of ADC $(\triangle \mathrm{ADC}$ : $0.18 \times$ $10^{-3}$ vs $\left.0.05 \times 10^{-3} \mathrm{~mm}^{2} / \mathrm{s}, p=0.04\right)$ and $\alpha(\Delta \alpha: 0.03$ vs $0.01, p<0.01$ ) were significantly bigger in CR group patients. No significant differences were found in $\mathrm{D}_{\text {fast }}-\mathrm{T} 0$, $\mathrm{D}_{\text {fast }}-\mathrm{T} 1, \Delta \mathrm{D}_{\text {fast }}, \mathrm{f}_{\mathrm{p}}-\mathrm{T} 0, \mathrm{f}_{\mathrm{p}}-\mathrm{T} 1, \Delta \mathrm{f}_{\mathrm{p}}, \mathrm{DDC}-\mathrm{T} 1, \Delta \mathrm{DDC}, \alpha-\mathrm{T} 0$ and $\alpha$-T1 between the two groups $(p>0.05)$.

\section{ROC analysis of MRI parameters}

The results of ROC analyses of DWI-derived parameters were presented in Table 4 and Fig. 3. The ROC analysis indicated that $\mathrm{ADC}-\mathrm{T} 1$ showed the highest predictive value, with an AUC of 0.880 , closely followed by $\Delta \alpha$ (AUC $=0.869$ ). The predictive values of $\mathrm{ADC}-\mathrm{T0}$, $\triangle \mathrm{ADC}, \mathrm{D}-\mathrm{T} 0, \mathrm{D}-\mathrm{T} 1$ and DDC-T0 were low, with AUCs below 0.80 . By adopting these parameters into treatment response prediction, ADC-T1 showed high predictive sensitivity of $83.78 \%$, specificity of $75.00 \%$, positive predictive value of $88.57 \%$ and negative predictive value of $66.67 \%$, while $\Delta \alpha$ showed high predictive sensitivity of $90.91 \%$, specificity of $75.00 \%$, positive predictive value of $85.71 \%$ and negative predictive value of $83.33 \%$.

\section{Discussion}

In present study, we applied multi-b-values DWI derived perfusion and diffusion parameters for ultra-early prediction of treatment response to CCRT in CC patients. The present study revealed the different perfusion and diffusion characteristics between $C R$ and non-CR group patients on the basis of MEM, BEM and SEM DWI

Table $\mathbf{2}$ Interobserver consistency of DWI derived parameters

\begin{tabular}{lll}
\hline & ICC & $95 \%$ confidence interval \\
\hline$A D C\left(\times 10^{-3} \mathrm{~mm}^{2} / \mathrm{s}\right)$ & 0.934 & $0.913-0.958$ \\
$D_{\text {slow }}\left(\times 10^{-3} \mathrm{~mm}^{2} / \mathrm{s}\right)$ & 0.913 & $0.891-0.936$ \\
$D_{\text {fast }}\left(\times 10^{-3} \mathrm{~mm}^{2} / \mathrm{s}\right)$ & 0.852 & $0.817-0.913$ \\
$\mathrm{f}_{\mathrm{p}}$ & 0.902 & $0.880-0.935$ \\
$\mathrm{DDC}\left(\times 10^{-3} \mathrm{~mm}^{2} / \mathrm{s}\right)$ & 0.919 & $0.905-0.943$ \\
$\mathrm{a}$ & 0.931 & $0.926-0.957$ \\
\hline
\end{tabular}

Note: ICC Intraclass correlation coefficient 
Table 3 Comparison of DWI derived parameters between patients with different treatment outcomes

\begin{tabular}{|c|c|c|c|c|}
\hline & $C R$ & non-CR & $t / z$ & $p$ \\
\hline$\overline{\mathrm{ADC}-\mathrm{TO}\left(\times 10^{-3} \mathrm{~mm}^{2} / \mathrm{s}\right)}$ & $1.08 \pm 0.20$ & $0.94 \pm 0.18$ & $189.50^{\mathrm{b}}$ & $0.02^{*}$ \\
\hline $\mathrm{ADC}-\mathrm{T} 1\left(\times 10^{-3} \mathrm{~mm}^{2} / \mathrm{s}\right)$ & $1.26 \pm 0.16$ & $1.00 \pm 0.16$ & $75.50^{b}$ & $<0.01^{*}$ \\
\hline$\triangle \mathrm{ADC}\left(\times 10^{-3} \mathrm{~mm}^{2} / \mathrm{s}\right)$ & $0.18 \pm 0.20$ & $0.05 \pm 0.17$ & $202.50^{b}$ & $0.04^{*}$ \\
\hline $\mathrm{D}_{\text {slow }}{ }^{-\mathrm{T} 0}\left(\times 10^{-3} \mathrm{~mm}^{2} / \mathrm{s}\right)$ & $0.93 \pm 0.15$ & $0.76 \pm 0.13$ & $4.12^{\mathrm{a}}$ & $<0.01^{*}$ \\
\hline $\mathrm{D}_{\text {slow }}-\mathrm{T1}\left(\times 10^{-3} \mathrm{~mm}^{2} / \mathrm{s}\right)$ & $1.07 \pm 0.16$ & $0.92 \pm 0.16$ & $3.31^{\mathrm{a}}$ & $<0.01^{*}$ \\
\hline$\Delta \mathrm{D}_{\text {slow }}\left(\times 10^{-3} \mathrm{~mm}^{2} / \mathrm{s}\right)$ & $0.14 \pm 0.24$ & $0.17 \pm 0.21$ & $0.36^{\mathrm{a}}$ & 0.72 \\
\hline$D_{\text {fast }}-{ }^{-T 0}\left(\times 10^{-3} \mathrm{~mm}^{2} / \mathrm{s}\right)$ & $71.63 \pm 14.82$ & $69.78 \pm 15.57$ & $253.50^{b}$ & 0.25 \\
\hline$D_{\text {fast }}{ }^{-T 1}\left(\times 10^{-3} \mathrm{~mm}^{2} / \mathrm{s}\right)$ & $88.59 \pm 10.13$ & $82.83 \pm 15.32$ & $215.50^{b}$ & 0.06 \\
\hline$\Delta D_{\text {fast }}\left(\times 10^{-3} \mathrm{~mm}^{2} / \mathrm{s}\right)$ & $16.95 \pm 20.31$ & $13.06 \pm 21.27$ & $284.5^{\mathrm{ob}}$ & 0.57 \\
\hline$f_{p}-T_{0}$ & $0.26 \pm 0.06$ & $0.25 \pm 0.06$ & $289.50^{b}$ & 0.64 \\
\hline$f_{p}-T 1$ & $0.28 \pm 0.06$ & $0.28 \pm 0.07$ & $308.00^{b}$ & 0.90 \\
\hline$\Delta f_{p}$ & $0.02 \pm 0.07$ & $0.03 \pm 0.10$ & $286.00^{b}$ & 0.59 \\
\hline DDC-TO $\left(\times 10^{-3} \mathrm{~mm}^{2} / \mathrm{s}\right)$ & $1.20 \pm 0.29$ & $1.02 \pm 0.27$ & $2.31^{\mathrm{a}}$ & $0.02^{*}$ \\
\hline DDC-T1 $\left(\times 10^{-3} \mathrm{~mm}^{2} / \mathrm{s}\right)$ & $1.29 \pm 0.28$ & $1.29 \pm 0.27$ & $0.07^{a}$ & 0.94 \\
\hline$\Delta \mathrm{DDC}\left(\times 10^{-3} \mathrm{~mm}^{2} / \mathrm{s}\right)$ & $0.08 \pm 0.44$ & $0.28 \pm 0.31$ & $1.66^{\mathrm{a}}$ & 0.10 \\
\hline a-TO & $0.65 \pm 0.10$ & $0.66 \pm 0.06$ & $0.22^{a}$ & 0.82 \\
\hline$a-T 1$ & $0.68 \pm 0.10$ & $0.67 \pm 0.06$ & $0.41^{\mathrm{a}}$ & 0.68 \\
\hline$\Delta a$ & $0.03 \pm 0.02$ & $0.01 \pm 0.01$ & $3.59^{a}$ & $<0.01^{*}$ \\
\hline
\end{tabular}

Note: Data are expressed as mean \pm SD. ${ }^{*} p<0.05$

${ }^{a}$ Comparisons were performed by independent $\mathrm{t}$ test. ${ }^{\mathrm{b}}$ Comparisons were performed by Mann-Whitney U test

models. The results of this study showed that pretreatment diffusion parameters including $\mathrm{ADC}-\mathrm{T} 0, \mathrm{D}_{\text {slow }}-\mathrm{T} 0$, and DDC-T0 were significantly higher in CR group patients. Pretreatment CR group patients possess better water diffusion property than non-CR group patients, which may be due to relative loose cellularity or consistent distribution. This resulted in higher sensitivity to treatment regime in $\mathrm{CR}$ group patients. Better perfusion of the tumor helps delivery of cytotoxic drugs as well as oxygen during radiation therapy [10], but we didn't find difference between $\mathrm{D}_{\text {fast }}$ and $f_{\mathrm{p}}$, this may be caused by the complexity of microcirculation perfusion.

Moreover, our study demonstrated that the completion of 3rd day can be a feasible time-point to monitor and predict treatment response. Baseline ADC, $\mathrm{D}_{\text {slow }}$, DDC exhibited diagnostic ability, but diagnostic potency was higher for ADC-T1 and $\Delta \alpha$. By monitoring DWI parameters on 3rd day, we can raise accuracy in differentiating patients with different treatment response. Previous studies demonstrated that change of tumor diffusion property can be used as indicator to screen out poor responders in CC patients underwent CCRT [29, 30]. We further advanced the monitoring time-point to the completion of third EBRT, and found that MEM, BEM and SEM DWI derived parameters showed significant difference between good and poor responders. Long before morphological tumor volume reduction, an early increase in water molecular diffusivity may be associated

Table 4 Sensitivity, specificity, PPV, and NPV of parameters at optimal cutoff values for differentiate patients with different treatment outcomes

\begin{tabular}{|c|c|c|c|c|c|c|}
\hline Parameters & AUC (95\%Cl) & Optimal cutoff value & Sensitivity (\%) & Specificity (\%) & PPV (\%) & NPV (\%) \\
\hline ADC-TO & $0.699(0.551-0.847)$ & $0.995\left(\times 10^{-3} \mathrm{~mm}^{2} / \mathrm{s}\right)$ & 82.14 & 52.00 & 65.71 & 72.22 \\
\hline ADC-T1 & $0.880(0.786-0.975)$ & $1.050\left(\times 10^{-3} \mathrm{~mm}^{2} / \mathrm{s}\right)$ & 83.78 & 75.00 & 88.57 & 66.67 \\
\hline$\triangle \mathrm{ADC}$ & $0.679(0.535-0.822)$ & $0.185\left(\times 10^{-3} \mathrm{~mm}^{2} / \mathrm{s}\right)$ & 94.12 & 47.22 & 45.71 & 94.44 \\
\hline $\mathrm{D}_{\text {slow }}-\mathrm{T0}$ & $0.787(0.663-0.910)$ & $0.760\left(\times 10^{-3} \mathrm{~mm}^{2} / \mathrm{s}\right)$ & 78.57 & 81.82 & 94.29 & 50.00 \\
\hline$D_{\text {slow }}{ }^{-T 1}$ & $0.774(0.629-0.919)$ & $0.990\left(\times 10^{-3} \mathrm{~mm}^{2} / \mathrm{s}\right)$ & 86.67 & 60.87 & 74.29 & 77.78 \\
\hline DDC-TO & $0.745(0.601-0.890)$ & $1.140\left(\times 10^{-3} \mathrm{~mm}^{2} / \mathrm{s}\right)$ & 88.46 & 55.56 & 65.71 & 83.33 \\
\hline$\Delta a$ & $0.869(0.768-0.970)$ & 0.022 & 90.91 & 75.00 & 85.71 & 83.33 \\
\hline
\end{tabular}

Note: AUC Area under the curve, PPV Positive predictive value, NPV Negative predictive value 

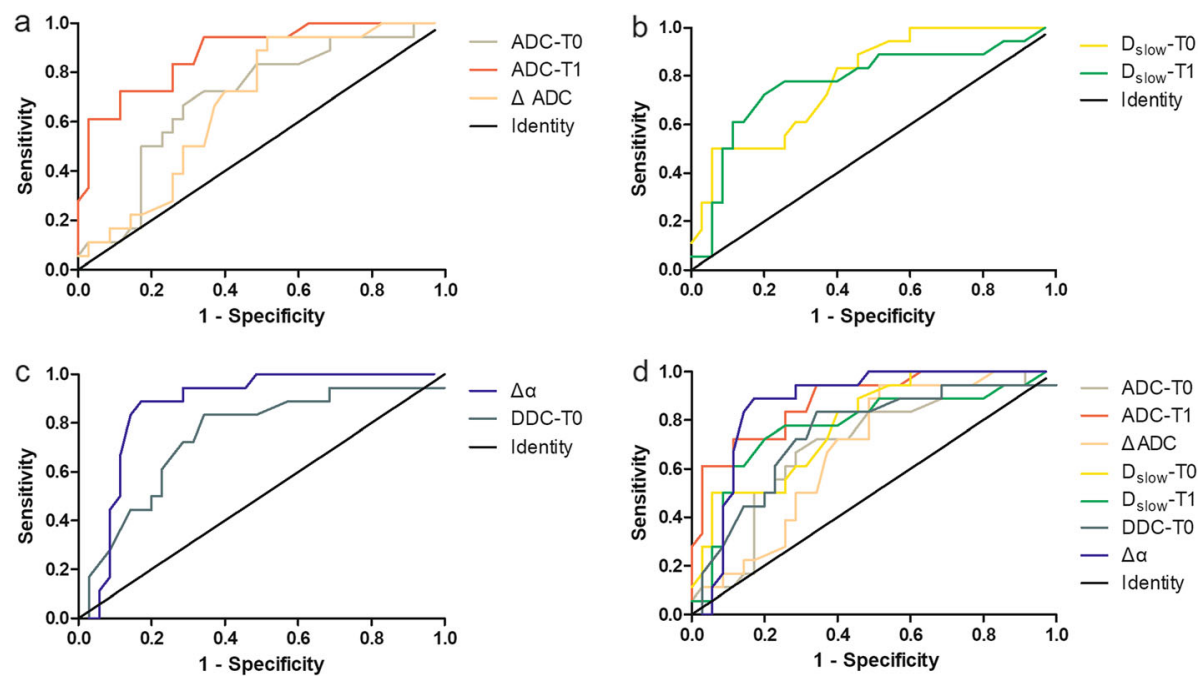

Fig. 3 ROC curves of DWI derived parameters in differentiating the good responders from poor responders. a The AUCs of MEM derived parameters ADC-T0, ADC-T1 and $\triangle A D C$ were $0.699,0.880$ and 0.679 , respectively. $\mathbf{b}$ The AUCs of BEM derived parameters $\mathrm{D}_{\text {slow }}{ }^{-T 0}$ and $\mathrm{D}_{\text {slow }}{ }^{-T 1}$ were 0.787 and 0.774. c The AUCs of SEM derived parameters $\triangle \mathrm{a}$ and DDC-T0 were 0.869 and 0.745 . $\mathbf{d}$ ADC-TI and $\Delta$ a showed higher diagnostic accuracy with AUCs above 0.8 among DWI derived parameters. ROC = receiver operating characteristic curves, $\mathrm{DWl}=$ diffusion-weighted imaging, $A U C s=$ areas under the curve

with the reduced tumor cellularity and destructive cell membrane integrity due to apoptosis and necrosis during chemoradiation [10]. By adopting multi-b-values DWI, we can quantitatively measure therapeutic reaction non-invasively in vitro at ultra-early time-point with high accuracy. This may provide supplementary information for prompt and individualized interventions for poor responders to economize medical expenditure and alleviate unnecessary toxicity and complications [31].

Compared with MEM and SEM, BEM derived parameters showed larger fluctuation and poor repeatability. The results in several BEM based studies varied. Wang et al. reported that $\mathrm{D}_{\text {slow }}$ values were significantly higher for the responders than non-responders before and 3 weeks after neoadjuvant chemotherapy treatment (NACT) initiation in CC patients [18], which was in consistent with our research. Bian et.al demonstrated that $\mathrm{ADC}_{\text {min }}$ and $\mathrm{ADC}_{\text {slow }}$ of good outcome group were significantly higher than those of poor outcome group. Moreover, at the 7th day of treatment, $\mathrm{f}$ and its change rate of good outcome group were significantly higher than those of poor outcome group [20]. Kato et al. reported that no significance was found before and during CRT at a dose of $20 \mathrm{~Gy}$, but the changes of $\mathrm{D}_{\text {slow }}$, $\mathrm{D}_{\text {fast }}$ and $f_{p}$ between the two time-points were significantly higher in CR group patients [24]. The above two studies had smaller cohort population and only used 4 and $6 \mathrm{~b}$ values to calculated BEM parameters, whereas previous studies used 10 or more b values to calculate BEM parameters in treatment response prediction, therefore this might cause bias in their research. We didn't find difference in $D_{\text {fast }}$ and $f_{p}$ before and during treatment between the two groups. During our research, we found that this might be caused by the poor repeatability and large fluctuation of $\mathrm{D}_{\text {fast }}$. Che et.al also reported this phenomenon [12]. Andreou et al. declared that these could be due to intra tumoral heterogeneity and noise variation [6]. Further research should be conducted in order to illustrate this fluctuation. The $\mathrm{f}_{\mathrm{p}}$ showed good repeatability but we didn't find difference between the two groups. The mechanism for an increase in $f_{p}$ is uncertain, but may reflect vascular normalization within tumors [13].

Unlike BEM, SEM was reported to show high precision and excellent repeatability, which was an important consideration when evaluating diffusion models for treatment response prediction $[13,14,31]$. The parameters obtained from SEM were highly repeatable, therefore they might be robust and could be employed as reliable quantitative tools. Our results also support this idea. SEM derived parameters have been used to assess and predict treatment response in brain, breast, rectal, prostate tumors [11, 14, 32, 33]. A very strong positive relationship between $\mathrm{ADC}, \mathrm{D}_{\text {slow }}$ and $\mathrm{DDC}$ was found $[13,34]$. This may indicate that they are sensitive to the same tissue characteristics and provide similar information. CR group CC patients with the higher DDC-T0 might be more sensitive to drugs within the microenvironment. Tumors with higher cellular and glandular pleomorphism tend to have higher level of intravoxel diffusion heterogeneity thus a lower $\alpha$ [14]. Zhu et al. reported that $\Delta \alpha$ was higher in patients achieved 
pathological complete response in locally advanced rectal cancer patients [5], which was consistent with our result. Several studies have shown that high-grade or highstage tumors exhibited lower $\alpha$ values [29,33], thereby the increase of $\alpha$ values could be interpreted as the tumor is less aggressive and more sensitive to treatment. Zhang et.al also compared value of MEM, BEM and SEM models in treatment response prediction of CC patients. They found that ADC, $\mathrm{D}_{\text {slow }}$ and $\mathrm{DDC}$ was lower in responders than in non-responders groups, and $\alpha$ was higher in responders group than in non-responders group [35], which was inconsistent with our result. This might be caused by the difference in observation endpoint. Zhang et.al defined responders as CR or PR patients, and CR was defined as who appeared as CR at anytime during 12 months, while we determined treatment outcome at 1 month after the completion of CCRT. They depicted that higher DDC represented more necrosis and poorer oxygenation, which resulted in extended radiotherapy resistance, thus DDC was higher in non-responder group. But we considered that since DDC was the continuous distribution of ADC within voxel, higher DDC represented better water diffusion property resulting in better radio- and chemo- sensitivity. So higher DDC was observed in patient with better treatment response.

There were several limitations in this study. First, the regions of interest were selected in the maximal solid parts of the tumors instead of the entire tumors, which might lead to selection bias owing to histological heterogeneity of tumors. Second, the follow-up time was relatively short and longer follow-ups needed for further confirmation of our results. Third, more monitoring time-points should be set in order to observe the dynamic changes of parameters as some parameters fluctuate during treatment. Our results were preliminary conclusion and further investigation was going to be proceeded.

\section{Conclusion}

The 3rd day may be a critical ultra-early time-point to assess and predict treatment response. Multi-b-values DWI derived parameters $\mathrm{ADC}-\mathrm{T} 1$ and $\Delta \alpha$ have great potential for ultra-early prediction of treatment response of CCRT in CC patients.

\footnotetext{
Abbreviations

a: Intravoxel diffusion heterogeneity index; ADC: Apparent diffusion coefficient; AUC: Area under the curve; BED: Biological effective dose; BEM: Bi-exponential model; CC: Cervical cancer; CCRT: Concurrent chemoradiotherapy; CR: Complete response; DDC: Distributed diffusion coefficient; $D_{\text {fast }}$ : Pseudo-diffusion coefficient; $D_{\text {slow: }}$ Pure diffusion coefficient; DWI: Diffusion-weighted imaging; EBRT: External beam radiotherapy; FIGO: Federation of Gynecology and Obstetrics; $\mathrm{f}_{\mathrm{p}}$ : Perfusion fraction; ICBT: Intracavitary brachytherapy; ICC: Intra-class correlation coefficient; IVIM: Intravoxel incoherent motion; MEM: Mono-exponential model; NACT: Neoadjuvant chemotherapy treatment; NPV: Negative predictive value;
}

PPV: Positive predictive value; ROC: Receiver operating characteristic curves; SEM: Stretched exponential model

\section{Acknowledgements}

Not applicable.

\section{Authors' contributions}

YH conceived and designed this study. GWZ, ZS, MQW and WHH conducted the study. BXH and LCW collected important background data. BL and WLM drafted the manuscript. All authors read and approved the final manuscript. $\mathrm{BL}$ and WLM equally contributed to this work.

\section{Funding}

This work was supported by Chinese National Natural Science Foundation Grants (No. 81220108011). The funding sponsors had estimated the feasibility of the study, but had no role in the collection, analysis, or interpretation of the data or in the decision to submit the manuscript for publication.

\section{Availability of data and materials}

The datasets analyzed in this study are available from the corresponding author on request.

\section{Ethics approval and consent to participate}

This research was approved by Xijing Hospital Ethic Committee and all participants consented to participate in this clinical research, and written informed consents were obtained from all patients before participation.

\section{Consent for publication}

Not Applicable.

\section{Competing interests}

Authors have no conflict of interests to declare.

\section{Author details}

${ }^{1}$ Department of Radiology, Xijing Hospital, Fourth Military Medical University, 127 Changle Western Road, Xi'an, P. R. China 710032. ²Department of radiology, Longgang District People's Hospital, Shenzhen, Guangdong, P. R. China 518172. ${ }^{3}$ Department of Orthopaedics, Xijing Hospital, Fourth Military Medical University, 127 Changle Western Road, Xi'an, P. R. China 710032. ${ }^{4}$ Department of Radiation Oncology, Xijing Hospital, Fourth Military Medical University, 127 Changle Western Road, Xi'an, P. R. China 710032.

Received: 24 December 2019 Accepted: 6 August 2020

Published online: 14 August 2020

\section{References}

1. Le Bihan D, Breton E, Lallemand D, Aubin ML, Vignaud J, Laval-Jeantet M. Separation of diffusion and perfusion in intravoxel incoherent motion MR imaging. Radiology. 1988;168(2):497-505.

2. Le Bihan D. Intravoxel incoherent motion perfusion MR imaging: a wake-up call. Radiology. 2008;249(3):748-52.

3. Bennett KM, Schmainda KM, Bennett RT, et al. Characterization of continuously distributed cortical water diffusion rates with a stretchedexponential model. Magn Reson Med. 2003;50(4):727-34.

4. Liang CY, Chen MD, Zhao XX, et al. Multiple mathematical models of diffusion-weighted magnetic resonance imaging combined with prognostic factors for assessing the response to neoadjuvant chemotherapy and radiation therapy in locally advanced rectal cancer. Eur J Radiol. 2019;110: 249-55.

5. Zhu HB, Zhang XY, Zhou XH, et al. Assessment of pathological complete response to preoperative chemoradiotherapy by means of multiple mathematical models of diffusion-weighted MRI in locally advanced rectal cancer: a prospective single-center study. J Magn Reson Imaging. 2017; 46(1):175-83.

6. Andreou A, Koh DM, Collins DJ, et al. Measurement reproducibility of perfusion fraction and pseudodiffusion coefficient derived by intravoxel incoherent motion diffusion-weighted MR imaging in normal liver and metastases. Eur Radiol. 2013;23(2):428-34.

7. Lambrecht M, Vandecaveye $V$, De Keyzer F, et al. Value of diffusionweighted magnetic resonance imaging for prediction and early assessment 
of response to neoadjuvant radiochemotherapy in rectal cancer: preliminary results. Int J Radiat Oncol Biol Phys. 2012;82(2):863-70.

8. Paudyal R, Oh JH, Riaz N, et al. Intravoxel incoherent motion diffusionweighted MRI during chemoradiation therapy to characterize and monitor treatment response in human papillomavirus head and neck squamous cell carcinoma. J Magn Reson Imaging. 2017;45(4):1013-23.

9. Hauser $T$, Essig $M$, Jensen $A$, et al. Prediction of treatment response in head and neck carcinomas using IVIM-DWI: evaluation of lymph node metastasis. Eur J Radiol. 2014;83(5):783-7.

10. Kim S, Loevner L, Quon H, et al. Diffusion-weighted magnetic resonance imaging for predicting and detecting early response to chemoradiation therapy of squamous cell carcinomas of the head and neck. Clin Cancer Res. 2009;15(3):986-94.

11. Bedair R, Priest AN, Patterson AJ, et al. Assessment of early treatment response to neoadjuvant chemotherapy in breast cancer using non-monoexponential diffusion models: a feasibility study comparing the baseline and mid-treatment MRI examinations. Eur Radiol. 2017:27(7):2726-36.

12. Che $S$, Zhao X, Ou Y, et al. Role of the Intravoxel incoherent motion diffusion weighted imaging in the pre-treatment prediction and early response monitoring to Neoadjuvant chemotherapy in locally advanced breast Cancer. Medicine (Baltimore). 2016:95(4):e2420

13. Reischauer C, Patzwahl R, Koh DM, et al. Non-mono-exponential analysis of diffusion-weighted imaging for treatment monitoring in prostate Cancer bone metastases. Sci Rep. 2017;7(1):5809.

14. Liu X, Zhou L, Peng W, et al. Comparison of stretched-exponential and monoexponential model diffusion-weighted imaging in prostate cancer and normal tissues. J Magn Reson Imaging. 2015;42(4):1078-85.

15. Zheng $H$, Ren $W$, Pan $X$, et al. Role of intravoxel incoherent motion MRI in early assessment of the response of esophageal squamous cell carcinoma to chemoradiotherapy: a pilot study. J Magn Reson Imaging. 2018;48(2): 349-58.

16. Winfield JM, Orton MR, Collins DJ, et al. Separation of type and grade in cervical tumours using non-mono-exponential models of diffusionweighted MRI. Eur Radiol. 2017;27(2):627-36.

17. Lin M, Yu X, Chen Y, et al. Contribution of mono-exponential, bi-exponential and stretched exponential model-based diffusion-weighted MR imaging in the diagnosis and differentiation of uterine cervical carcinoma. Eur Radiol. 2017:27(6):2400-10.

18. Wang YC, Hu DY, Hu XM, et al. Assessing the early response of advanced cervical Cancer to Neoadjuvant chemotherapy using Intravoxel incoherent motion diffusion-weighted magnetic resonance imaging: a pilot study. Chin Med J. 2016;129(6):665-71.

19. Zhu L, Zhu L, Shi H, et al. Evaluating early response of cervical cancer under concurrent chemo-radiotherapy by intravoxel incoherent motion MR imaging. BMC Cancer. 2016;16:79.

20. Bian H, Liu F, Chen S, et al. Intravoxel incoherent motion diffusion-weighted imaging evaluated the response to concurrent chemoradiotherapy in patients with cervical cancer. Medicine (Baltimore). 2019;98(46):e17943.

21. Bakke KM, Hole KH, Dueland S, et al. Diffusion-weighted magnetic resonance imaging of rectal cancer: tumour volume and perfusion fraction predict chemoradiotherapy response and survival. Acta Oncol. 2017;56(6): 813-8.

22. Hou J, Guerrero M, Suntharalingam $M$, et al. Response assessment in locally advanced head and neck cancer based on RECIST and volume measurements using cone beam CT images. Technol Cancer Res Treat. 2015;14(1):19-27.

23. Mazeron R, Castelnau-Marchand P. Escande A, et al. Tumor dose-volume response in image-guided adaptive brachytherapy for cervical cancer: a meta-regression analysis. Brachytherapy. 2016;15(5):537-42.

24. Kato H, Esaki K, Yamaguchi T, et al. Predicting early response to Chemoradiotherapy for uterine cervical Cancer using Intravoxel incoherent motion MR imaging. Magn Reson Med Sci. 2019;18(4):293-8.

25. Yan C, Xu J, Xiong W, et al. Use of intravoxel incoherent motion diffusionweighted MR imaging for assessment of treatment response to invasive fungal infection in the lung. Eur Radiol. 2017;27(1):212-21.

26. Eisenhauer EA, Therasse P, Bogaerts J, et al. New response evaluation criteria in solid tumours: revised RECIST guideline (version 1.1). Eur J Cancer. 2009; 45(2):228-47.

27. Le Bihan $D$, Breton $E$, Lallemand $D$, et al. MR imaging of intravoxel incoherent motions: application to diffusion and perfusion in neurologic disorders. Radiology. 1986;161 (2):401-7.
28. Lai V, Lee VH, Lam KO, et al. Intravoxel water diffusion heterogeneity MR imaging of nasopharyngeal carcinoma using stretched exponential diffusion model. Eur Radiol. 2015;25(6):1708-13.

29. Onal C, Erbay G, Guler OC. Treatment response evaluation using the mean apparent diffusion coefficient in cervical cancer patients treated with definitive chemoradiotherapy. J Magn Reson Imaging. 2016;44(4):1010-9.

30. Kuang F, Yan Z, Wang J, et al. The value of diffusion-weighted MRI to evaluate the response to radiochemotherapy for cervical cancer. Magn Reson Imaging. 2014;32(4):342-9.

31. Orton MR, Messiou C, Collins D, et al. Diffusion-weighted MR imaging of metastatic abdominal and pelvic tumours is sensitive to early changes induced by a VEGF inhibitor using alternative diffusion attenuation models. Eur Radiol. 2016;26(5):1412-9.

32. Bai Y, Lin Y, Tian J, et al. Grading of Gliomas by using Monoexponential, Biexponential, and stretched exponential diffusion-weighted MR imaging and diffusion kurtosis MR imaging. Radiology. 2016;278(2):496-504.

33. Kwee TC, Galban CJ, Tsien C, et al. Intravoxel water diffusion heterogeneity imaging of human high-grade gliomas. NMR Biomed. 2010;23(2):179-87.

34. Wu $Q$, Zheng $D$, Shi L, Liu M, Wang M, Shi D. Differentiating metastatic from nonmetastatic lymph nodes in cervical cancer patients using monoexponential, biexponential, and stretched exponential diffusionweighted MR imaging. Eur Radiol. 2017:27(12):5272-9.

35. Zhang H, Zhou Y, Li J, et al. The value of DWI in predicting the response to synchronous radiochemotherapy for advanced cervical carcinoma: comparison among three mathematical models. Cancer Imaging. 2020;20(1):8.

\section{Publisher's Note}

Springer Nature remains neutral with regard to jurisdictional claims in published maps and institutional affiliations.
Ready to submit your research? Choose BMC and benefit from:

- fast, convenient online submission

- thorough peer review by experienced researchers in your field

- rapid publication on acceptance

- support for research data, including large and complex data types

- gold Open Access which fosters wider collaboration and increased citations

- maximum visibility for your research: over $100 \mathrm{M}$ website views per year

At $\mathrm{BMC}$, research is always in progress.

Learn more biomedcentral.com/submissions 